ITH Congress, $\}$ HOUSE OF REPRESENTATIVES. \{ Dooument 2d Session.

Water-Supply and Irrigation Paper No. 189

Series L, Quality of Water, 17

DEPARTMENT OF THE INTERIOR

UNITED STATES GEOLOGICAL SURVEY

CHARLES 1). WALCOTT, DIRECTOR

\title{
THE PREVENTION OF STREAM POLLUTION BY STRAWBOARD WASTE
}

\section{U. S. GEOLOGICAL SURVEY,}

BY

ROLLA, MO.

\section{EARLE BERNARD PHELPS}

\begin{abstract}
In cooperation with the Sanitary Reseakch Labor ، tory and Sewage Experiment Station of the Massachusetts

INSTITUTE OF TECHNOLOGY
\end{abstract}

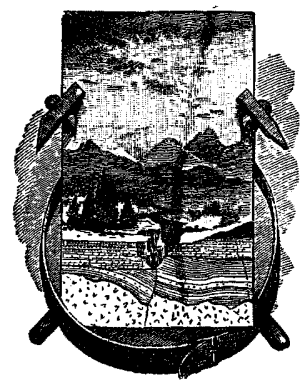

W ASHIN GTON

GOVERNMENT PRINTING OFFICE

1906 



\section{0 N T E N TS.}

Tage.

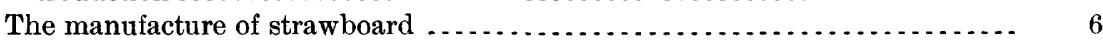

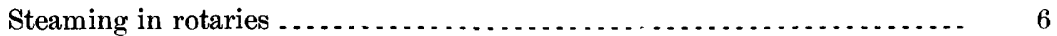

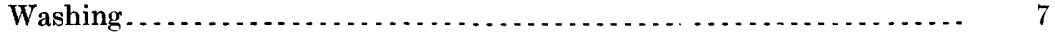

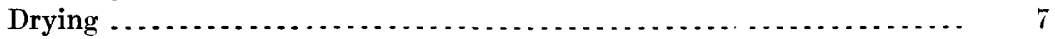

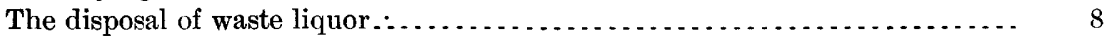

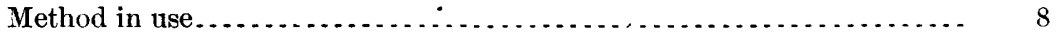

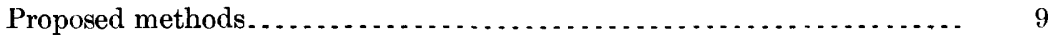

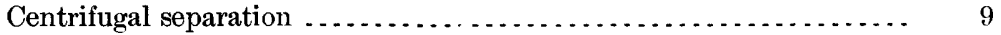

Precipitation with carbon dioxide ........................... 9

Laboratory investigations .......................................... 10

Chemical study of the soluble matter ........................ 10

Precipitation experiments.................................... 10

Sedimentation experiments ................................... 12

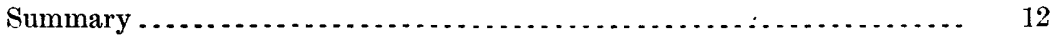

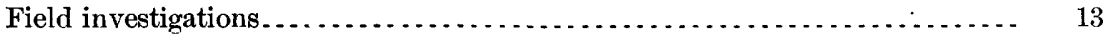

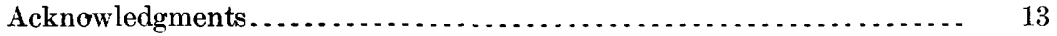

Amount of water used ........................................ 13

Raw material and finished product ........................... 15

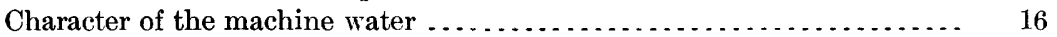

Mechanical filtration ......................................... 16

Description of the filter .................................. 16

Preliminary sedimentation ................................ 19

Amount of wash water................................... 20

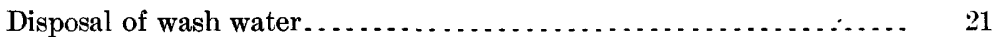

Character of effluent...................................... 21

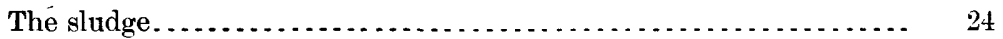

Amount and composition .............................. 24

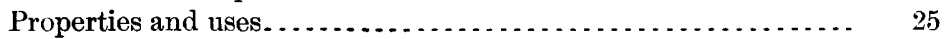

Résumé of method of treatment........................... 26

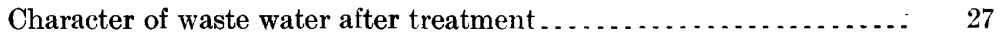

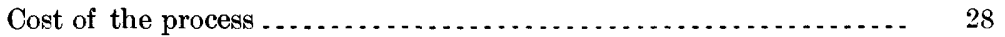

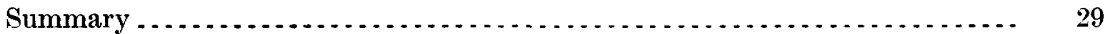

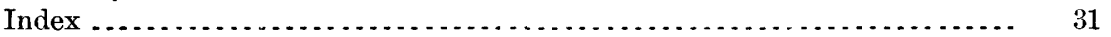

\section{L L USTRATI I N S.}

Plate I. $A$, View of strawboard mill; $B$, Piles of baled straw ..............

II. $A$, Sedimentation tanks and float regulator; $B$, Experimental filter, sedimentation tanks, and measuring tank

Fic. 1. Details of experimental filter ............................. 17

2. Sectional view of standard orifice.......................... 18 



\title{
THE PREVENTION OF STREAM POLLUTION BY STRAWBOARD WASTE: ${ }^{a}$
}

\author{
By Earle Bernard Phelps.
}

INTRODUCTION.

The disposal of the waste liquors resulting from the manufacture of strawboard forms one of the most important problems connected with the prevention of stream pollution. In 1900 the total production of strawboard in the United States was 157,534 tons at 59 factories. For each ton of strawboard manufactured there were discharged into the streams about 65,000 gallons of waste liquor that contained 1,173 pounds of straw and mineral matter and 490 pounds of lime. The total waste discharged into the streams in 1900 amounted to $10,239,710,000$ gallons of liquor, containing $184,777,382$ pounds of straw and mineral matter and $77,191,660$ pounds of lime. This enormous waste was discharged by 59 plants of various sizes, but as most of these mills are along small streams the resulting pollution is very apparent. Some idea of the amount of this pollution may be obtained from Pl. I, $B$. The baled straw shown is a three months' supply for a mill having an output of 30 tons a day. In three months one third of this straw will be discharged into the stream as waste matter.

The problem of the disposal of the waste water has been studied by Prof. R. L. Sackett, of Earlham College, ${ }^{b}$ and the present investigation is a continuation of the work of Sackett along new lines. In approaching the problem it is necessary to keep constantly in mind the economic conditions affecting the industry. The low selling price of the product, the immense volume of waste water necessary, and the fact that competition between strawboard and other forms of cheap board is active, make it quite impracticable for the manufacturers to

aThis investigation was made in cooperation with the Sanitary Research Laboratory and sewage Experment Station of the Massachusetts Institute of Technology.

$b$ Water-Sup. and 1rr. Paper No. 113, U. S. Geol. Survey, 1905, pp. 9-35. 
adopt any process involving serious expenditures. The solution of the problem must be sought in a process which will show an actual saving. Aside from the matter of the recovery of by-products of commercial value, this means that the process must compete in cost with the present unsatisfactory sedimentation methods employed at many of the mills, to the cost of which may reasonably be added the almost constant expense of lawsuits and injunction proceedings, the latter in some cases causing the closing of the mill.

As a result of this study it has been found that sedimentation of the waste water for a short period, followed by filtration thru sand at high rates-the so-called mechanical filtration, but without coagulants-will produce an effluent from which more than 90 per cent of the suspended organic matter has been removed. This effluent, while not ideal, is probably purified to such an extent that, allowing a factor of safety of 2 for impurities in the stream, it may be discbarged into streams having a minimum flow of twice the discharge of the mill without producing a nuisance. The cost of filtration by this process, after the initial cost of installation, is practically reduced to the cost of pumping the wasb water. The final result is a heavy sludge, whose volume is less than 5 per cent of the initial volume of the waste. Ultimate disposal of this sludge could be made either by discharge over land for spontaneous evaporation, by evaporation by means of artificial heat, or by filter pressing. The sludge has some value as a fertilizer, and there are also certain commercial uses to which it seems to be adapted.

\section{THE MANUFACTURE OF STRAWBOARD.}

The following description of the manufacture of strawboard is taken from Professor Sackett's paper: ${ }^{a}$

STEAMING IN ROTARIES.

The straw is first subjected to a cooking process by steam and lime. A-large ellipsoidal rotating steel boiler called a "rotary" $* * *$ is filled with straw, which is then cooked down with steam, then again filled and cooked down until the rotary boiler has been completely filled. The process of filling a rotary occupies from six to twelve hours. The final charge consists of about 6 tons of straw and 30 bushels, or 2,100 pounds, of lime in the form of milk. This mixture is then rotated and cooked under 40 pounds of steam pressure for twelve hours. *** This apparently severe chemical and mechanical action results in a rapid softening of the woody fiber and in the reduction of the straw to a dark-yellow, pulpy mass. This "stock," as it is called, is stacked in piles 10 to 15 feet high to drain. Concerning the action which takes place in the rotaries, the Journal of the Society of Chemical Industry says: $b$

"The chemical action of the milk of lime on the incrusting materials surrounding the straw fiber is not a vigorous one. These incrusting materials are not completely, 
U. S. GEOLOGN IL SURVEY

WATER-SUPPLY PAPER NO. 189 PL, I

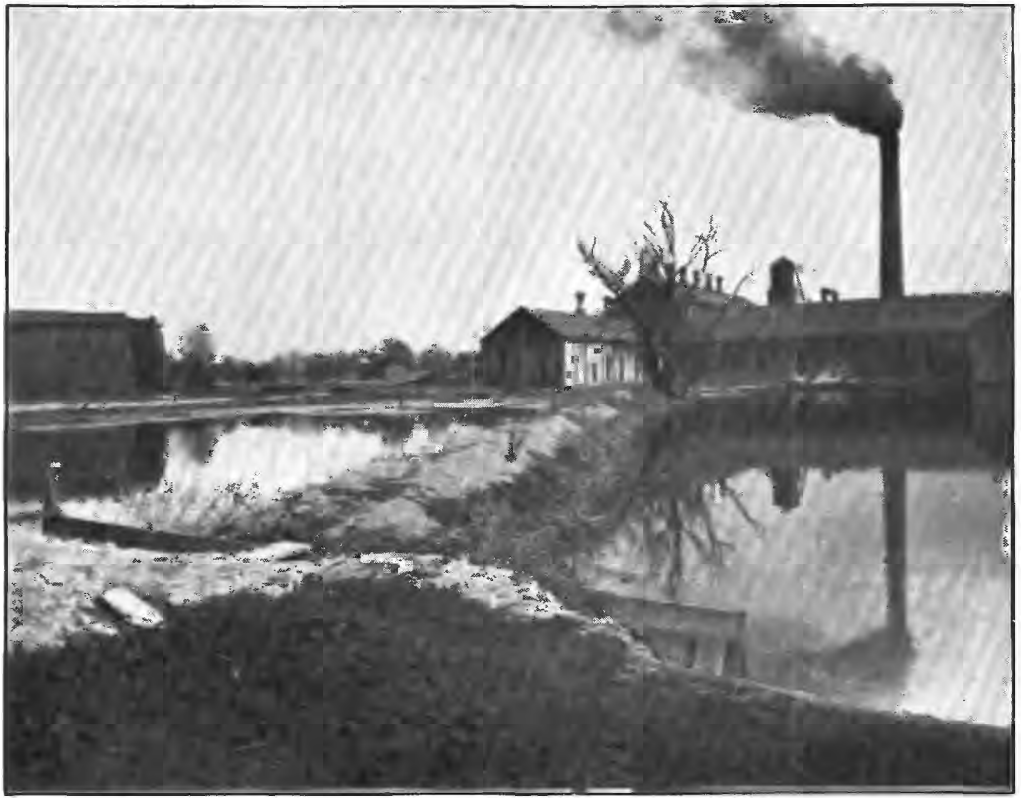

A. VIEW OF STRAWBOARD MILL.

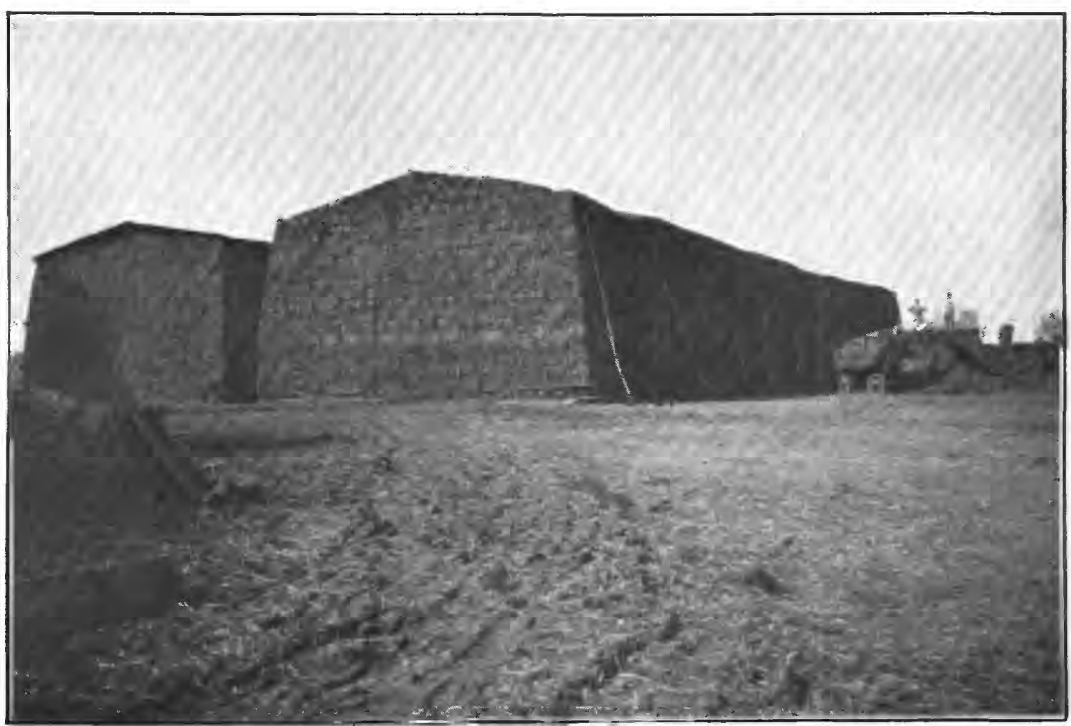

B. PILES OF BALED HAY.

One-third, by weight, will be wasted in three months. 

nor, indeed, to a great extent, separated from the cellulose. The mineral matter remains in the product practically untouched, and if any less quantity than that corresponding to the percentage in the original straw operated upon exists in the prepared pulp, it is due rather to the washing after digestion than to any solvent action of the milk of lime. Milk of lime under certain conditions has a bleaching action upon the straw. It neutralizes the organic acids usually found when fibrous plants are heated for any length of time in the presence of water."

The yield of pulp at this point will be from 75 to 80 per cent of the weight of the original material.

The material is allowed to stand in these piles for twenty-four hours or more to drain. After it is thus drained it contains about 50 per cent of water and from 6 to 7 per cent of lime. This is equivalent to from 12 to 14 per cent of lime in the dry straw. Since the original charge of lime and straw was in the proportion of 2,100 pounds of lime to 14,100 pounds of straw and lime, or about 14 per cent lime, practically none of the latter has drained out with the condensed steam. This drainage from the stock piles forms but a small part of the waste sewage. It is straw colored and very turbid, carrying a small quantity of fiber broken fine in the rotaries.

WASHING.

This process is much more drastic, and it is here that the great volume of waste is produced.

The stock is run thru washing machines for the purpose of removing the lime. * * * The washing machine consists of an oval channel about 3 feet wide, around which the stock travels, being supplied with copious volumes of water. Across this channel is placed a cylinder, 42 inches in diameter and 42 inches long, having longitudinal ribs or flanges about three-fourths of an inch square in section and threefourths of an inch apart. Meshing with this, like the teeth of geared wheels, is an idler, below, of similar size and form. These wheels, revolving, lift the water and straw to a level several inches higher than that in the oval channel, whence it flows by gravity halfway around its course to a point where it meets a revolving brass screen of fine mesh, thru which a part of the water escapes, carrying with it the finer particles of fiber and free lime. The remaining straw, with additional volumes of fresh water, now passes many times thru the rolls, which further mash and break the fiber, and around to the screen, where more straw, lime, and water escape. $* * *$

DRYING.

After the washing process the straw, with a considerable volume of water, is led to a train of rolls, consisting of three parts-first, the wet end; second, the hot rolls; third, the trimming and cutting machine. As it comes from the washers the material is run into vats, where it is mixt with large quantities of water and past over hollow cylinders having fine wire-cloth faces, which allow the water to escape, leaving the fiber on the surface of the cylinder. The fiber is then taken by woolen felts, which are prest down on the surface of the cylinder. This makes a web of paper on the felt. The pulp, which is now about one-third straw and two-thirds water, travels up and down, over and under a double train of hot rolls, heated by steam that is carried in thru hollow bearings. As the pulp passes on thru the train it is constantly prest and dried, until finally it is separated from its cloth support and goes to the trimming machine, where it is cut into sheets of proper size. It now contains about 10 per cent of water and a small quantity of lime. The board is manufactured in many thicknesses and weights. Just before it is trimmed it may be coated on one or both sides with a thin paper facing or finish. 
THE DISPOSAL OF WASTE LIQUOR.

METHOD IN USE.

At present, so far as can be learned, the only method of treating the waste liquor in actual use by the manufacturers is that of prolonged sedimentation in open fields. The overflow water from these fields is not satisfactorily clarified at all times of the year. During cold weather it is fairly clear and can be discharged witbout serious harm. During the summer, however, a very offensive fermentation takes place in the accumulated sludge, giving rise to objectionable odors and blackening the water. At such times the aim is to hold all the waste water in the ponds, trusting to evaporation and to the storage capacity of the ponds until cold weather again relieves the situation and the increased flow of the stream permits a discharge of the surplus water stored. The most serious objection to this process, which seems to be satisfactory to riparian owners below, is the fact that these ponds are continually filling up with a soft mud, which destroys their function as sedimentation basins and renders them useless for other purposes. The time must come, even in the most favorable situation, when additional land can not be afforded for this purpose. A second objection is that the accumulated sludge is held for years and slowly putrefies. The organic matter of the waste is but slightly nitrogenous and is fairly stable. It probably contains some reducing sugars capable of rapid fermentation if kept in concentrated form and if given at the same time some nitrogenous matter. The slow decomposition of the stable straw material supplies the necessary nitrogen, and the result is a very rapid multiplication of the putrefactive organisms and an accompanying offensive putrefaction. Laboratory experiments have shown that the soluble sugars by themselves, as found in a filtered sample of the waste water, do not ferment or decompose, and that even the unfiltered waste is not subject to a quick putrefaction such as characterizes sewage matter. In fact, bottles have been stored for over a year without any evidence of fermentation, and it may very reasonably be held that the necessary nitrogen comes largely from the bottom of the ponds, rather than from the sludge itself. Inspection of the stream below one of these ponds showed that, wbile putrefaction was barely noticeable and not at all offensive in the pond itself, the admixture of some of this water with that of a small brook, highly polluted with the refuse of a slaughterhouse, had immediately a very offensive result. Investigation of the condition of the streams below these mills reveals the fact that the most serious nuisance generally occurs at a point very remote from the mill itself. It is directly caused by the slow decomposition of material deposited in the bed of the stream. The conditions are doubtless aggravated by the simultaneous precipitation of 
other polluting substances, notably sewage, brought about by the free lime of the strawboard waste.

The effective solution of the problem lies in the rapid separation of the solid matter from the dissolved sugars and lime and a subsequent dilution of the latter so that they shall be innocuous. The insoluble material when dry is entirely stable. The present system, therefore, is not only unsatisfactory from the economic side, but it works on a wrong principle for satisfactory purification in that it encourages putrefaction.

The cost of these ponds at four of the larger mills of the United Box-board and Paper Company, as stated hy an official of that company, has been, in round numbers, to date, $\$ 10,000, \$ 15,000, \$ 18,000$, and $\$ 8,000$. In the last case the results were still unsatisfactory, and after a considerable expenditure on other experiments the company has been obliged to close this mill.

\section{PROPOSED METHODS.}

CENTRIFUGAL SEPARATION.

Centrifugal separation of the solid matter from the liquor was tried at Tiffin, Ohio, in 1904. It has not been possible to obtain more definite information concerning those experiments than iscontained in the trade papers of that time. It is understood, however, that the results were quite satisfactory, but that the cost of operation was prohibitive. The account referred to (see Paper Trade Journal, February 2, 1905) states that the effluent was clear and colorless and that the residue was found by analysis to be valuable as a fertilizer.

PRECIPITATION WITH CARBON DIOXIDE.

As a result of his investigations Sackett concluded that plain sedimentation would remove about 10 per cent of the suspended solids in twenty-four hours and that during the ensuing twenty-four hours ihe additional removal was very slight; that good purification could be effected by chemical precipitation only by using sulfate of aluminum in excessive amounts and at an entirely prohibitive cost; that sulfate of iron gave inferior and unsatisfactory results, and, finally, that by a process of precipitation with carbon dioxide and lime an average removal of 85 per cent of the suspended matter could be effected.

The process recommended by Sackett consists in $(a)$ saturation of the waste water with carbon dioxide to form bicarbonate with all the lime present; $(b)$ addition of lime equal to that already present to form a normal carbonate; $(c)$ sedimentation of the precipitated carbonate and consequent dragging down of some of the organic matter, and $(d)$ filtration of the resulting claritied liquor thru sand at rates of 500,000 to 2,000,000 gallons per acre per day. This process has never been used by manufacturers so far as the writer is aware. 
It does not appear from Sackett's report that he tried the simpler but equivalent process of saturating one-half the total volume with carbon dioxide and then mixing with the other half. Such treatment would doubtless have precipitated the calcium fully as well, with a saving of one-half the carbon dioxide and all the lime required by the process recommended. An examination of the analytical data shows that the removal of suspended organic matter accomplished by the precipitation and sedimentation processes varied from zero to 75 per cent, with a mean value of 37 per cent. Experiments on plain sedimentation, made by the writer both in the laboratory and on a large scale in the field, show it to be equally efficient for the removal of suspended organic matter. The fact is that the precipitated carbonate of calcium is very finely divided and has no value as a coagulant. The process is valuable to remove the lime, if that be desirable. It hardly seems, however, that the value of discharging a lime-free effluent into the hard waters of the Middle West is at all commensurate with the cost of treatment.

\section{LABORATORY INVESTIGATIONS.}

\section{CHEMICAL STUDY OF THE SOLUBLE MATTER.}

Several barrels of the strawboard waste liquor were shipped to Boston from one of the mills of the United Box-board and Paper Company, and on this material a series of investigations was carried out. Sackett's experiments with various coagulants were repeated and his results confirmed. It was found that the poor results obtained with any but excessive amounts of iron or aluminum sulfate were due to the presence of a substance in solution which forms soluble combinations with those metals. This substance was isolated by precipitation with hydrochloric acid, and after repeated purification was found to have the following properties: It is an organic acid, probably related to the humic or ulmic acids of the soil and peaty waters. It exists in the waste water as a calcium salt, having partially neutralized the free lime used in the digestion. It is precipitated by strong acids, coming out as a dark-red substance which turns brown on slow oxidation in the air. It can be redissolved in a solution of sodium carbonate, giving a garnet-red solution. It dissolves in alcohol, giving a deepred color, but oxidizes to a brown insoluble substance. Its calcium and aluminum salts are not soluble when prepared from the insoluble acid, but the acid can not be precipitated from its solutions by these metals. It appears that there are formed colloidal suspensions of the calcium and aluminum salts. The solutions have a bright-yellow color and colloidal appearance. The iron compound is similar but of a green color. The sodium salt appears to be soluble and to dissociate into deeply colored acid ions. 
A second substance isolated from the waste has the following properties: It is soluble in water and not precipitated by any of the common precipitants, including alum, ferrous sulfate, lead acetate (normal or basic), carbonates, hydrates, or acids. It is responsible for a large part of the color of the water and can not be removed by any practical method.

These two substances with the lime make up the greater part of the dissolved material. They are entirely stable and do not undergo putrefactive change when stored in the incubator, either alone or mixt with varying proportions of tap water. In addition to these substances small amounts of reducible sugars are present. The amount is so small that in any material dilution of the liquor the dilution of these sugars will prevent their manifesting themselves as putrefactive agents. These sugars are probably responsible for the slow fermentation in the sedimentation fields after the lime has been sufficiently removed to allow the action to proceed.

\section{PRECIPITATION EXPERIMENTS.}

Substances in suspension may be removed by filtration or by sedimentation. When the material is finely divided or of low specific gravity, either process may sometimes be assisted by the application of suitable coagulants. These tend to clot the small particles into larger flakes, and by their own greater density carry the clotted material to the bottom. Two chemical substances are required, as a rule, to produce the necessary precipitation, one of which is generally the calcium bicarbonate found normally in the water. This calcium salt reacts with the sulfates of certain metals, notably iron or aluminum, to produce the sulfate of calcium and the hydrates of the corresponding metals. In the present case there is a large amount of free lime in solution. It would seem, therefore, that precipitation might be brought about by the addition of either copperas or alum. Experiments showed that copperas failed to react at all and that fair results could be obtained with alum, but only at a prohibitive cost. As will be seen in the accompanying tables of results, the removal of organic matter by alum was much better than that obtained by plain sedimentation.

Results of precipitation experiment on strawboard wasie.

\begin{tabular}{c} 
Sample. \\
\hline
\end{tabular}

a The coagulant used was alum in the proportion of 10 grains of sulfate of aluminum per gallon. 
Increasing the amount of aluminum sulfate gave practically the same result. Smaller amounts gave indefinite and at times negative results. The use of 10 grains per gallon of sulfate of aluminum at 1 cent a pound would represent a cost of about 43 cents per ton of finished product of the mill. The studies on the nature of the dissolved material already referred to explain these poor precipitation results with alum. Soluble compounds are formed with the organic acid, instead of aluminum bydrate, the desired coagulant.

Experiments were made with carbon dioxide according to Sackett's procedure, and his results were confirmed. There was but a slight removal of suspended organic matter-about 30 per cent-which could be produced equally well by plain sedimentation. In fact, under actual working conditions sedimentation was found to be even more effective.

\section{SEDIMENTATION EXPERIMENTS.}

In a study of plain sedimentation it is important to know the rate of sedimentation and how this varies with the time. With satisfactory data on this point it is possible to estimate the amount of clarification which may be expected to result from any given period of sedimentation and to establish the most suitable period for the case in hand. It was observed early in this work that apparently a large portion of the suspended solids settled out in a very short time, and that to all appearances further improvement was extremely slow. The determinations of the total solids given in the following table show that there is no practical advantage in sedimentation for a period of much over one hour:

Effect of sedimentation on strawboard waste.

\begin{tabular}{|c|c|c|}
\hline & \multicolumn{2}{|c|}{ Suspended solids. } \\
\hline & Present. & Removed. \\
\hline Liquor at beginning of experiment & $\begin{array}{l}\text { Parts per } \\
\text { million. } \\
1,344\end{array}$ & Percent. \\
\hline $\begin{array}{l}\text { Supernatant after } 1 \text { hour } \ldots \ldots \ldots \ldots \ldots \\
\text { Supernatant after } 12 \text { hours }\end{array}$ & $\begin{array}{r}548 \\
494\end{array}$ & 6 \\
\hline
\end{tabular}

SUMMARY.

As a summary of the laboratory investigations, it may be said that the removal of the dissolved coloring and other organic matter and the lime in an econonical way is impractical; that by plain sedimentation a removal of suspended material practically as good as the best removal observed with the use of a coagulant can be accomplished; and that a sedimentation period of one hour is sufficient for the remoral of about 60 per cent of the suspended solids, a longer period increasing this removal but slightly. For the removal of the remainder of the suspended matter, there remains but one process-filtration. It was therefore decided to make an actual field test of this method of 
purification. The very large amounts of suspended matter to be handled seemed to eliminate at the outset the possible use of slow sand filtration, so that it was obvious that mechanical filtration at high rates and with some provision for removing the accumulated sludge from the surface of the filters was the only system applicable to the problem.

FIELD INVESTIGATIONS.

ACKNOWLEDGMENTS.

In March and April, 1905, a visit was made to one of the mills of the United Box-board and Paper Company, at Urbana, Ohio. Every opportunity was given the writer to make a thoro study of the processes of manufacture, and it is here desired to make suitable acknowledgments to $\mathrm{Mr}$. Rush E. Evans, division manager, and to Mr. D. C. Amerine, superintendent, for the many courtesies extended, both on that occasion and during the subsequent visit for the installation of an experimental plant.

\section{AMOUNT OF WATER USED.}

It was found that conditions were favorable for measuring the entire volume of waste water, as it left the mill in a waste flume. As a check on these measurements, observations of the rate of operation of the pump were made, all the water used being pumped from a large well under the mill.

A rectangular flume, whose mean width was 1.96 feet, was used for these measurements. A distance of 100 feet was measured off in a portion where the slope was practically constant. To determine the velocity of flow at various elevations in the flume, a float was used which was nearly as long as the width of the flume and was provided with vanes underneath, so that it always floated squarely across the flume. The following observations are the mean of a large number made at various elevations of water in the flume:

Mean depth, velocity, and flow of waste water in flume of mill of United Box-bourd and Paper Company, Urbana, Ohio.

\begin{tabular}{|c|r|r|r|}
\hline $\begin{array}{c}\text { Depth of } \\
\text { water. }\end{array}$ & $\begin{array}{c}\text { Velocity } \\
\text { of flow. }\end{array}$ & $\begin{array}{c}\text { Area of } \\
\text { cross sec- } \\
\text { tion. }\end{array}$ & Flow. \\
\hline & \begin{tabular}{r|r} 
Feet per \\
Foot.
\end{tabular} & second. & Square foot. \\
0.19 & 3.1 & 0.37 & $\begin{array}{c}\text { Cubic feet } \\
\text { per second. }\end{array}$ \\
.25 & 3.8 & .49 & 1.1 \\
.29 & 4.0 & .57 & 1.9 \\
.31 & 4.2 & .61 & 2.3 \\
.33 & 4.3 & .65 & 2.6 \\
.37 & 4.5 & .72 & 3.2 \\
\hline
\end{tabular}

These values of the depth and the corresponding flow were then plotted. The most probable line was drawn thru them, and that curve was used as the true rating curve of the flume in the subsequent calculations. 
During the two hours from 10.45 a. m. to 12.45 p. m., March 30 , a test run was made to determine the total flow. The following readings of the elevation of the water in the waste flume were made, and from these readings has been calculated the total flow for the two hours:

Flow of waste water in flume of mill of Cinited Box-board and Paper Company, Urbana, Ohio, March 30, 1905.

\begin{tabular}{|c|c|c|c|c|}
\hline \multirow{2}{*}{ Time. } & \multirow{2}{*}{ Depth. } & \multirow{2}{*}{ Flow. } & \multicolumn{2}{|c|}{$\begin{array}{l}\text { Flow for } 15 \text {-minute } \\
\text { period. }\end{array}$} \\
\hline & & & $\begin{array}{l}\text { Mean rate } \\
\text { of flow. }\end{array}$ & Total flow. \\
\hline 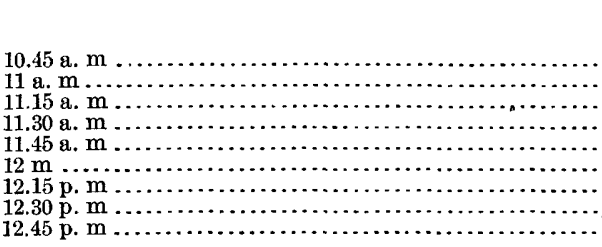 & $\begin{array}{r}\text { Fuot. } \\
0.29 \\
.29 \\
.33 \\
.33 \\
.33 \\
.33 \\
.38 \\
.36 \\
.33\end{array}$ & \begin{tabular}{|r} 
Cubic feet \\
per second. \\
2.3 \\
2.3 \\
2.8 \\
2.8 \\
2.8 \\
2.8 \\
3.4 \\
3.1 \\
2.8
\end{tabular} & \begin{tabular}{|r} 
Cubic feet \\
per second. \\
\hdashline .3. \\
2.6 \\
2.6 \\
2.8 \\
2.8 \\
2.8 \\
3.1 \\
3.2 \\
3.0
\end{tabular} & $\begin{array}{r}\text { Cubicfeet. } \\
2,100 \\
2,300 \\
2,500 \\
2,500 \\
2,500 \\
2,800 \\
3,000 \\
2,700\end{array}$ \\
\hline Total.... & & & ............ & 20,400 \\
\hline
\end{tabular}

This total flow of 20,400 cubic feet in two hours represents an average flow of 2.69 cubic feet per second.

A few measurements were made of the water running in the waste flume when the beaters were not running and again when the paper machine was stopt. The flow from the machine was found to be fairly constant at 1.4 cubic feet per second, and the beaters were found to discharge amounts of 1.2 to 1.8 cubic feet per second, depending on the number of beaters in operation at the time.

During the test run observations of the rate of operation of the pump were made at short intervals. The pump was a double-acting duplex Smith-Vaile pump, with water cylinders 14 inches in diameter and with a stroke of 15 inches. Slip being neglected, the capacity of the pump is, therefore, 1.335 cubic feet per stroke, or 5.340 cubic feet per complete revolution. Following are the observations made on the pump and the calculated rate of pumping:

Discharge of pump at mill of United Box-board and Paper Company, Urbana, Ohio, March 30, 1905.

\begin{tabular}{|c|c|c|c|c|c|}
\hline \multirow{2}{*}{ Time. } & \multirow{2}{*}{$\begin{array}{l}\text { Revolu- } \\
\text { tions per } \\
\text { minute. }\end{array}$} & \multirow{2}{*}{ Discharge. } & \multirow{2}{*}{$\begin{array}{c}\text { Time be- } \\
\text { tween ob- } \\
\text { servations. }\end{array}$} & \multicolumn{2}{|c|}{$\begin{array}{l}\text { Discharge of pump be- } \\
\text { tween nbservations. }\end{array}$} \\
\hline & & & & Mean. & Total. \\
\hline 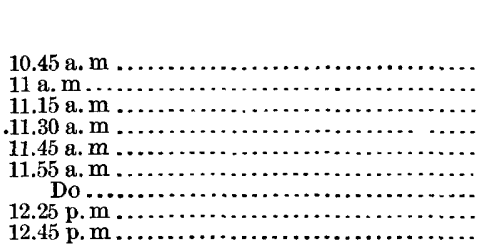 & \begin{tabular}{r|} 
\\
31 \\
30 \\
30 \\
30 \\
30 \\
30 \\
$a 40$ \\
40 \\
38
\end{tabular} & $\begin{array}{r}\text { Cubic feet } \\
\text { per second. } \\
2.28 \\
2.67 \\
2.67 \\
2.67 \\
2.67 \\
2.67 \\
3.58 \\
3.58 \\
3.57\end{array}$ & \begin{tabular}{|r|} 
Seconds. \\
0 \\
900 \\
900 \\
900 \\
900 \\
600 \\
1,800 \\
1,200
\end{tabular} & $\begin{array}{r}\begin{array}{r}\text { Cubic feet } \\
\text { per second. }\end{array} \\
2.43 \\
2.67 \\
2.67 \\
2.67 \\
2.67 \\
\ldots . \\
3.58 \\
3.48\end{array}$ & $\begin{array}{r}\text { Cubic feet. } \\
2,457 \\
2,403 \\
2,403 \\
2,403 \\
1,602 \\
\ldots \ldots \\
6,444 \\
4.176\end{array}$ \\
\hline Total pumped $\ldots \ldots \ldots \ldots \ldots \ldots$ & $\ldots \ldots$ & $\ldots \ldots \ldots \ldots$ & $\ldots \ldots \ldots \ldots$ & $\ldots \ldots \ldots \ldots$ & 21,888 \\
\hline
\end{tabular}


During the test four of the seven rotaries were filled. Two hundred and fifty cubic feet of water are required for each rotary, or 1,750 cubic feet for the seven. Since all seven are filled only once in twentyfour hours the water used in this process amounts to 73 cubic feet per hour for the whole day. The water so used during the two hours of the test was, however, 750 cubic feet, an excess of 604 cubic feet over the normal mean consumption. The amount pumped must, therefore, be corrected by this amount. The elevation of the water in the supply tank was 1 foot greater at the end of the test than at the start. The diameter of the tank is 12 feet. This storage amounts, therefore, to 113 cubic feet, and must also be applied as a correction. A small stream of water was being wasted from the engine condenser. This stream was roughly estimated by float measurements to be about 0.3 cubic foot per second, or 2,160 cubic feet during the two hours of the run. These three corrections amount to 2,888 cubic feet, which is to be subtracted from the total pumped, 21,888 cubic feet, leaving a net pumpage of 19,000 cubic feet for two hours, or 2.64 cubic feet per second, a result in close agreement with the 2.69 cubic feet per second measured in the waste flume.

\section{RAW MATERIAL AND FINISHED PRODUCT.}

During this test run, careful weighings were made of the amount of finished board produced. The figures were as follows:

Product of mill of Cinited Box-board and Paper Company, Urbana, Ohio, for two hours, March 30, 1905.

Pounds.

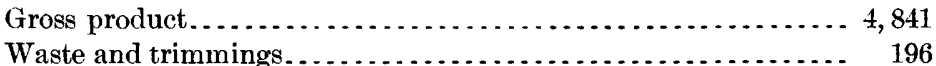

Net product. ............................ 4,645

Dividing the total amount of waste liquor, 20,400 cubic feet, by the amount of net product gives, 8,780 cubic feet, or, roughly, 65,000 gallons per ton of product. As the daily product of this mill is about 30 tons, about 1,900,000 gallons of waste water are discharged each day.

The charge of one rotary was carefully weighed. There were used 133 bales of straw, of an average weight of 102 pounds, or a total of 13,600 pounds of straw. The amount of lime was weighed, but the weight was somewhat in excess of the average amount used, as determined by the total weekly consumption of lime. The latter figure, which is 2,100 pounds per charge, will therefore be used. The total amount of straw used in the 7 rotaries is accordingly 95,200 pounds per day, and of lime, 14,700 pounds per day. Subtracting from this the 60,000 pounds of finished product leaves a waste of 35,200 pounds of vegetable and mineral matter from the straw and 14,700 pounds of lime, which is carried off each day in the 1.9 million gallons of water. 
Calculated into parts per million, these figures give about 2,400 parts of straw material and about 1,000 parts of lime. Analyses of average samples of the waste water gave about 600 parts of calcium or 840 parts of lime per million. The difference is due partly to the loss of lime during the draining of the digested pulp and largely to impurity of the lime.

\section{CHARACTER OF THE MACHINE WATER.}

Determinations of the lime were made on the well water and on the various waste waters. It was found that the greater part of the lime is washt out in the beaters and that the water from the machine contained but little lime in excess of that in the raw water. The actual figures were:

Calcium in waste water.

[Parts per million.]

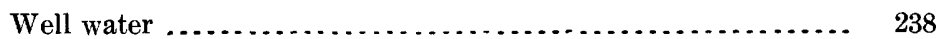

Beater water.......................................... 1, 164

Machine water................................... $\quad 380$

A rough determination of the impurities was made by precipitating the lime and organic matter, with a large excess of alum. A 6-inch column of the beater water gave a layer of precipitate an inch thick, while the amount obtained from the machine water was too small to be measured.

\section{MECHANICAL FILTRATION.}

In May, 1906, a small experimental filter was installed at this mill, in order to obtain some practical data on the efficiency of treating the waste by mechanical filtration. The filter and accessories were loaned by the New York Continental Jewell Filtration Company, of New York, thru the courtesy of Mr. R. E. Milligan, assistant general manager, and the expenses of shipment and installation were borne by the paper company.

DESCRIPTION OF THE FILTER.

The filter used is shown in fig. 1 . The waste water, after passing the regulating butterfly valve, divided into two streams and entered the bottoms of the two sedimentation tanks. These tanks were of cypress, each having a diameter of 4 feet and a depth to the overflow line of 3.2 feet. The capacity of the two was 603 gallons. The water was delivered to the tanks thru half-inch holes in the sides of risers extending to the surface. The vertical distribution was, therefore, very uniform. Vertical baffles caused the water to flow completely thru the tanks, and a funnel-shaped overflow collected the clarified water from the surface of each tank and delivered it to the surface of the filter. The filter proper was of galvanized iron, set 
upon a cast-iron base, provided with a false bottom of fine brass screening. The djameter of the filter was 20 inches, and its total depth to the false bottom was 5 feet. Suitable connections and valves

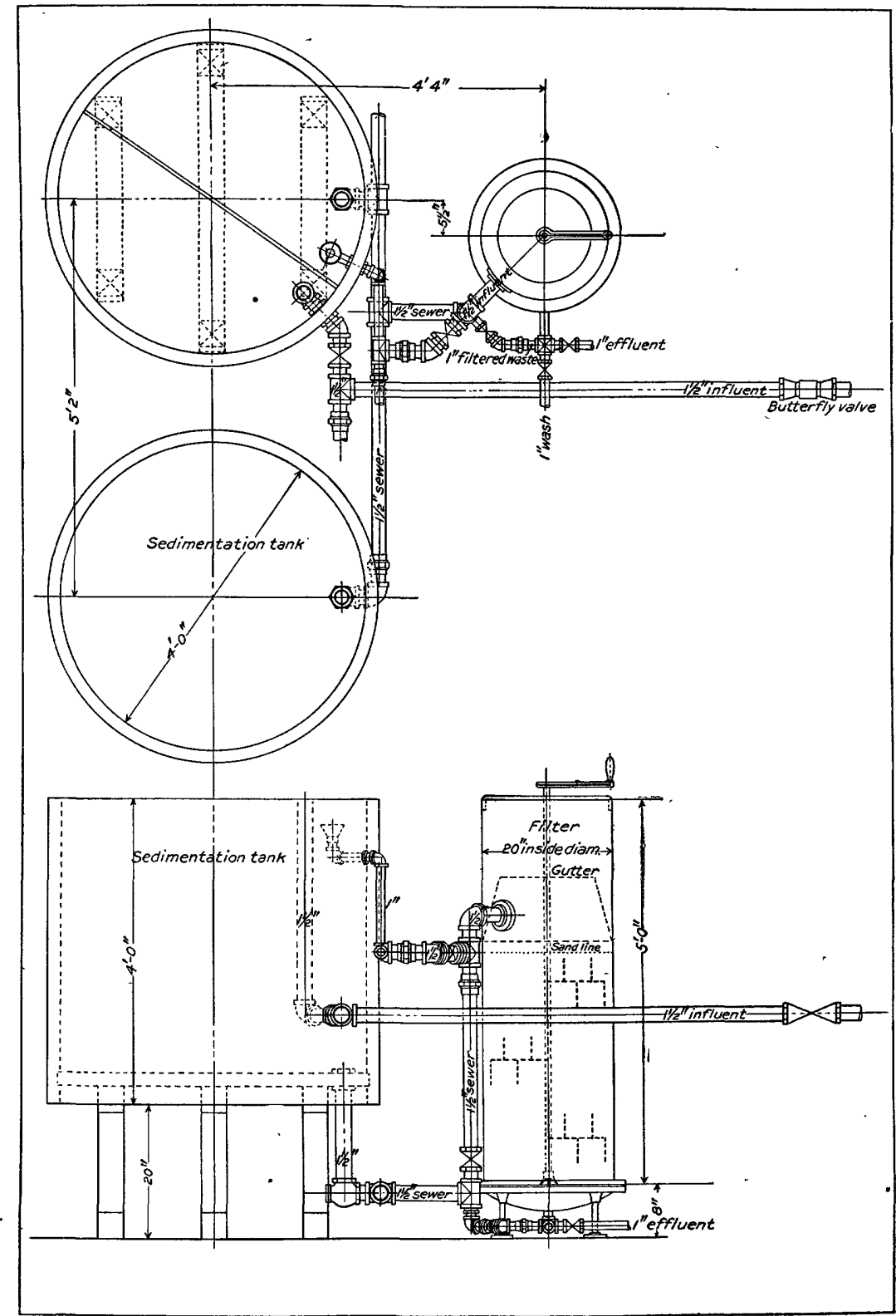

FIG. 1.-Details of experimental filter.

were provided, as shown in the drawing, so that the influent and the effluent water could be cut off, a stream of wash water could be IRR $189-06-2$ 
admitted from the bottom, and the dirty wash water, overflowing from the top, could either be wasted thru the sewer connection or returned to the sedimentation tanks. The device for stirring the sand during washing was operated by hand. Wash water was supplied from an elevated tank under such a head that a maximum flow of 25 gallons per minute, or 12 gallons per square foot per minute, was possible. A flow of about 8 gallons, per square foot per minute was generally used. Suitable connections were also made between the bottoms of the sedimentation tanks and the sewer. A 50-gallon barrel at the end of the sewer line served as a measuring tank for the wash water or the sludge. The rate of flow thru the filter was regulated at the outlet by a standard orifice, a sectional view of which is shown in fig. 2. The orifice itself was a trifle over seven-sixteenths

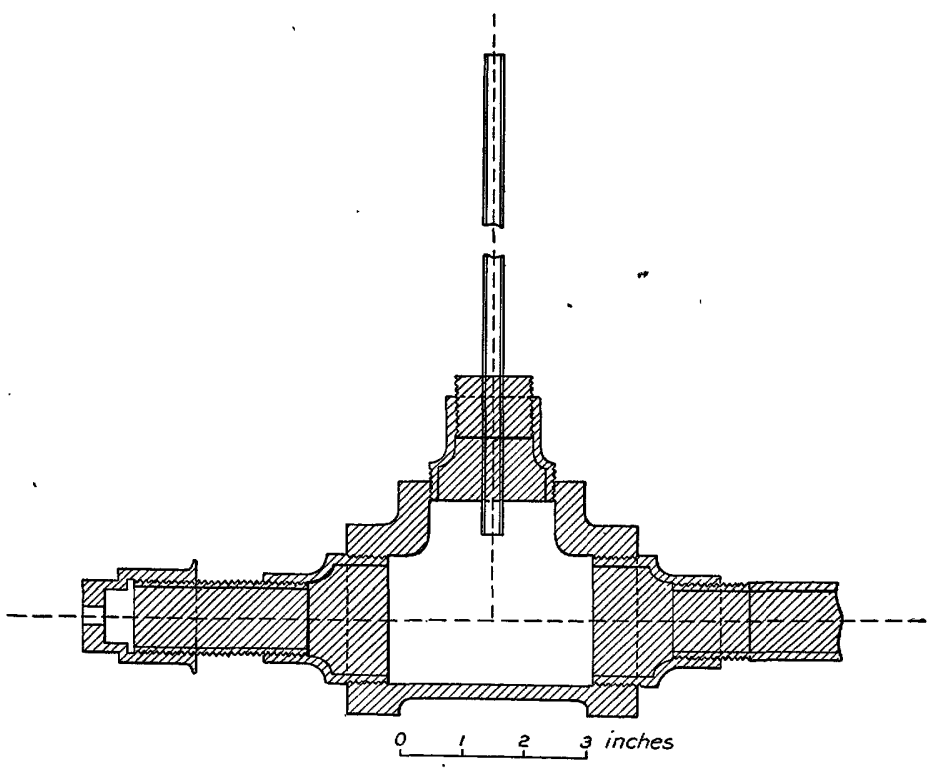

FIG. 2.-Sectional view of standard orifice.

of an inch in diameter. The brass cap containing the orifice was screwed over a nipple of 1 -inch pipe, which was in turn connected with a 2 -inch tee. The opposite side of this tee was connected by a short pipe to the valve regulating the outflow, and a glass tube, fitted to the upper opening of the tee, permitted the static head on the orifice to be read at any time. The large sectional area of the tee as compared with that of the orifice reduced the velocity of approach to a negligible value. This device was roughly calibrated in the field and was subsequently carefully calibrated by discharging into a large neasuring tank. The rough field values were found to be substantially correct. 


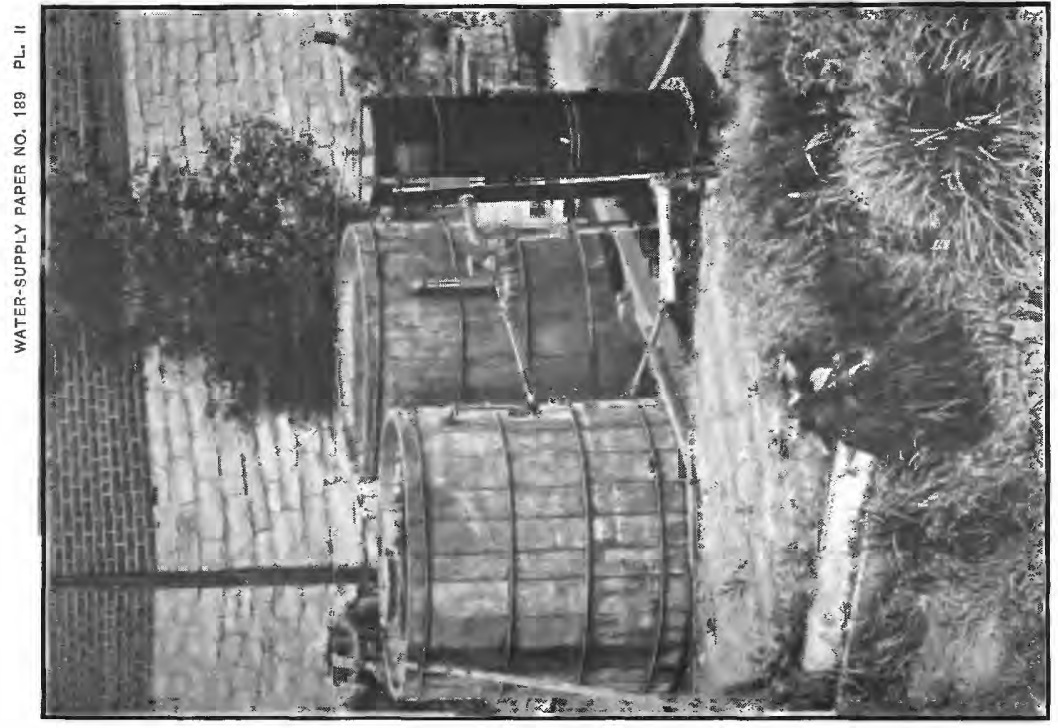

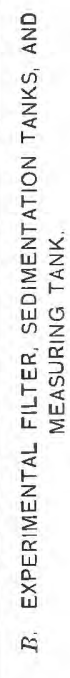

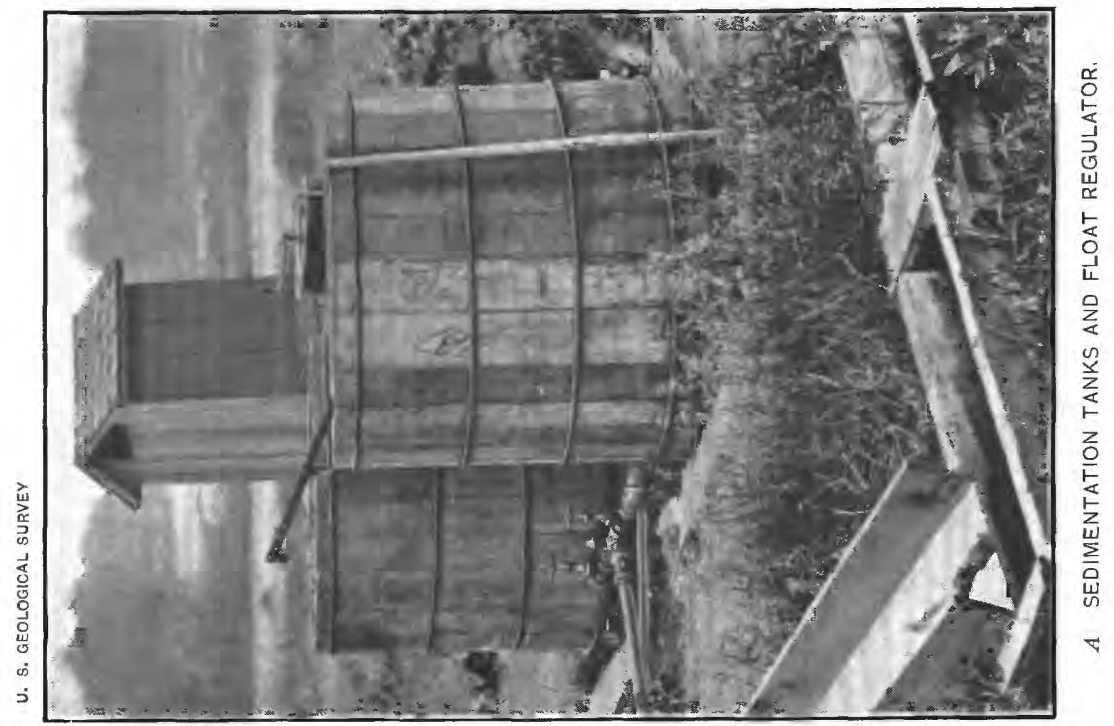



The rate of inflow to the tanks was adjusted to the rate of filtration by the butterfly valve, actuated by a float in one of the tanks (not shown). The filter was filled to a depth of 3 feet with clean 16-30 beach sand, i. e., sand which will all pass a sereen with 16 meshes to the linear inch and be retained on a screen with 30 meshes. The water line was 18 inches above the surface of the sand.

The appearance of the filter and sedimentation tanks as they were set up is well shown in Pl. II. Pl. II, $A$, shows the sedimentation tanks, the influent pipe and controlling valves, and the lever arm of the float operating the butterfly valve. Pl. II, $B$, shows the filter itself, the loss-of-head gage, and the connections with the tanks and the sewer. To the extreme right is the measuring tank, and passing between the two tanks on the ground the wash-water pipe line can be seen. The outlet of the filter is hidden from view behind the mound of earth in the foreground.

\section{PRELIMINARY SEDIMENTATION.}

A number of tests were first made to determine the rate of change in the loss of head during filtration with varying periods of preliminary sedimentation. A uniform rate of filtration of 3.25 gallons per minute, equivalent to a rate of $100,000,000$ gallons per acre per day, was maintained. The capacity of each of the sedimentation tanks was 300 gallons to the overflow line, so that one tank alone gave a mean storage capacity of one and one-half hours and the two tanks taken together three hours. During the first series of tests both sedimentation tanks were used. The following table shows the relation of loss of head to the quantity of water filtered, the run in question being a fair average of the five made in this way. The results of all the five tests were practically identical.

Relation of loss of head to quantity of water filtered.

\begin{tabular}{|c|c|c|c|}
\hline Time. & $\begin{array}{l}\text { Elapsed } \\
\text { time. }\end{array}$ & $\begin{array}{l}\text { Quantity } \\
\text { filtered. }\end{array}$ & $\begin{array}{l}\text { Loss of } \\
\text { head. }\end{array}$ \\
\hline 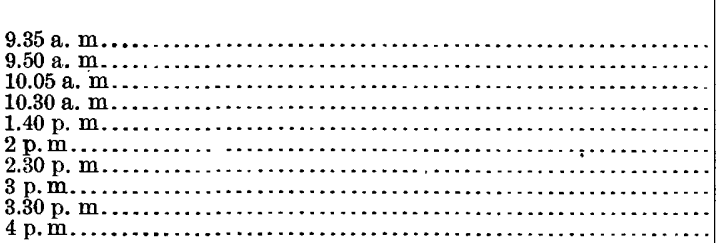 & $\begin{array}{r}\text { Minutes. } \\
0 \\
15 \\
30 \\
55 \\
55 \\
75 \\
105 \\
135 \\
165 \\
195\end{array}$ & $\begin{array}{r}\text { Gallons. } \\
0 \\
49 \\
98 \\
178 \\
178 \\
211 \\
308 \\
406 \\
504 \\
600\end{array}$ & $\begin{array}{r}\text { Inches. } \\
4 \\
7 \\
8 \\
12 \\
11 \\
14 \\
20 \\
28 \\
40 \\
55\end{array}$ \\
\hline
\end{tabular}

Between 10.30 a. m. and 1.40 p. m. test shut down. No liquor.

The maximum loss of head possible was 55 inches. The mean results from the above and four similar tests gave 585 gallons of water filtered before the loss of head was total. 
One of the sedimentation tanks was then cut out of service and the period of sedimentation correspondingly reduced to one and one-half hours. Four runs to determine the maximum amount which could be past under the conditions gave a mean result of 575 gallons, in practical agreement with that of the first series. It is apparent that a period of one and one-half hours was sufficient for the removal of that portion of the suspended matter which can be removed by sedimentation. An examination of the water during sedimentation in a glass vessel tended to confirm this conclusion. The suspended matter appears to be of two distinct kinds. One is very finely divided and light and does not settle out even on prolonged sedimentation. The other is granular and heavy and settles rapidly and completely. It was not convenient with the apparatus at hand to reduce further the period of sedimentation. The laboratory experiments quoted earlier in this paper indicated that a period of one hour would accomplish practically the same result as more prolonged sedimentation.

AMOUNT OF WASH WATER.

The pressure on the wash-water pipe line was sufficient to give an upward flow thru the filter of 25 gallons per minute, or about 12 gallons per minute per square foot of surface. In practise, flows of 8 to 10 gallons per square foot per minute were used. After each of the test runs just described, the filter was washt with an amount of water varying from 50 to 100 gallons for two and one-half to five minutes, the wash water being carefully measured. Observations of the surface of the filter showed plainly that the shorter period of washing was sufficient and that the longer periods did not in any case increase the quantity filtered during the succeeding run. The material deposited on the surface was exceedingly light and finely divided and required but little water for its removal. The stirring device used was not well adapted to the purpose, since there was little penetration of the sand by the suspended material. An air blast or some device which would thoroly agitate the surface before washing would undoubtedly make possible the use of still less wash water. Allowing 50 gallons for each wash, with an average quantity of 575 gallons per run filtered, gives a little less than 9 per cent wash water.

The loss of head in these tests bears out a fact of general observation, that the loss of head increases at a fairly constant rate during the run. Such being the case, it is quite evident that with a deeper filter the quantity filtered between washings would be proportionately increased. The amount of wasb water would, on the other hand, remain constant or increase but slightly. It is therefore safe to say that with a filter having an available loss of head of 9 to 12 feet an 
average run of six hours or more could be maintained and the amount of wash water could be reduced to less than 5 per cent.

DISPOSAL OF WASH WATER.

The process, as thus far described, is merely one of concentration of the suspended matter. If the above estimate of 5 per cent of wash water be correct and the filtered water be used for washing, the net result of the process would be the separation of 95 per cent of the water in comparatively clean form, leaving the total suspended impurity in the remaining 5 per cent of the water. This water might be spread upon a small area of land to evaporate, it might be evaporated by artificial means, or, if preferable, it might be filter prest; but the most economical way to dispose of it is to return it directly to the sedimentation tanks. The material on, the filter is so prest together into small lumps that it settles rapidly. The problem of the ultimate disposal of the sludge from the tanks will be taken up in another place.

CHARACTER OF EFFLUENT.

Complete chemical analyses of the waters before and after treatment during these experiments were neither desirable nor feasible. The determination of the total organic solids contained in the waters is the only analytical determination which would be of service in estimating the efficiency of the process. This determination might have heen made by the usual indirect method, i. e., by the difference between the total and the fixt or mineral solids. That determination is, however, not well adapted to field conditions, and small changes in the organic content would be entirely masked by the relatively large amount of mineral residue present. It was found in the laboratory studies on the waste liquor that estimating the efficiency of the various precipitation methods on the basis of this organic-solids determination and also on the basis of the oxygen-consumed method gave practically the same results. In other words, the organic matter present is fairly homogeneous in character, as might well be expected, and the oxygen-consumed figures, altho purely relative, are therefore a reliable measure of the amount of organic matter present. This test, therefore, and the determination of the turbidity, or suspended solids, by the well-known Jackson turbidimeter method, were used in this work to determine the quantity of the organic and the suspended matter, respectively.

During the two three-hour runs samples for analysis were collected every ten minutes from the raw liquor, sedimented liquor, and final effluent, the small samples being mixt together to obtain an average 
sample for the run. In both cases the rate was maintained at 3.25 gallons per minute. The following data of the test were obtained:

Data from test run of filter.

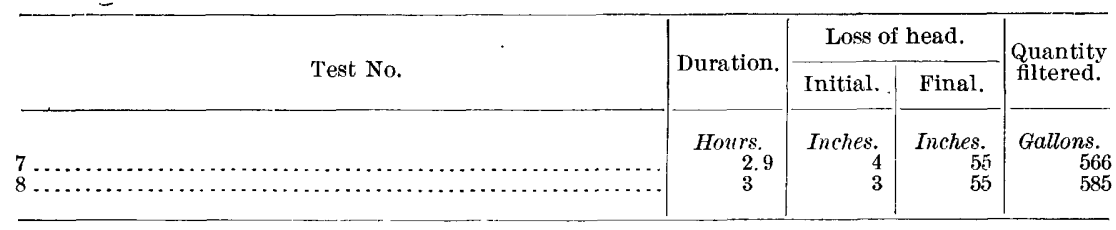

The chemical analyses for the two sets were very similar. The following table shows the mean values obtained:

Analyses of raw liquor, settled liquor, and effuent.

\begin{tabular}{|c|c|c|}
\hline & $\begin{array}{l}\text { Parts per } \\
\text { million. }\end{array}$ & $\begin{array}{l}\text { Per cent } \\
\text { removed. }\end{array}$ \\
\hline Oxygen consumed: & & \\
\hline 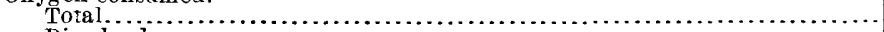 & 9,400 & \\
\hline Dissolved $\ldots \ldots \ldots \ldots \ldots \ldots \ldots$ & 2,000 & ... \\
\hline Suspended solids................................ & 28,000 & $\cdots$ \\
\hline Oxygen consumed: $\quad$ Settled liquor. & & \\
\hline Total................ & 6,200 & 34 \\
\hline Dissolved ....... & 1,600 & 20 \\
\hline 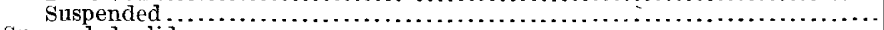 & 4,600 & 38 \\
\hline 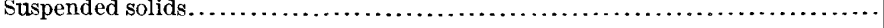 & 4,400 & 84 \\
\hline Oxygen consumed: & & \\
\hline Total............. & 2,200 & 77 \\
\hline Dissolved. & 1,700 & 15 \\
\hline 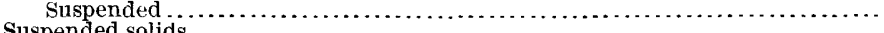 & 500 & 93 \\
\hline (n. & 575 & 98 \\
\hline
\end{tabular}

The appearance of the effluent frequently changed materially during the run. Contrary to expectations and general experience, the best effluent was always obtained during the early part of the run. The very first portions of effluent were generally slightly turbid, after which a perfectly clear water came thru, as a rule, entirely free from suspended matter. This state of affairs continued until the loss of head had reached about 6 or 8 inches, when the effluent suddenly became turbid and continued so uniformly until the end. The inference was that under a tension or pull on the surface film represented by about 6 to 8 inches of head the finely divided matter contained in the liquor was pulled thru the surface and then thru the filter. It was thought that if this should be a correct interpretation of the phenomenon, it might be obviated in one of two ways-by increasing the toughness of the surface deposit, or by decreasing the size of the sand pores by use of a layer of finer material on the surface. Botb of these methods were tried. 
To increase the density and toughness of the surface film the surface was covered with liquor, the outlet being closed, and 2 ounces of sulfate of aluminum were added and stirred in. Fifteen minutes were allowed for the formation and settling of the precipitate, and the filter was then started. The following data were obtained:

\section{Data of test run of filter after addition of alum.}

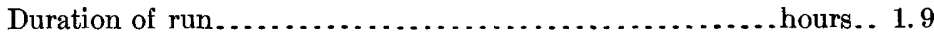

Loss of head:

Initial ....................................... 14

Final.............................................. 55

Quantity filtered ...................................... 370

The chemical analyses resulted as follows:

Analyses of raw liquor, of settled liquor, and of effuent after the addition of alum.

\begin{tabular}{|c|c|c|}
\hline . & $\begin{array}{l}\text { Parts per } \\
\text { million. }\end{array}$ & $\begin{array}{l}\text { Per cent } \\
\text { removed. }\end{array}$ \\
\hline Oxygen consumed: $\quad$ Raw liquor. & & \\
\hline Total.............. & 9,000 & $\cdots \ldots \ldots \ldots$ \\
\hline Suspended ............. & 7,400 & 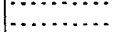 \\
\hline 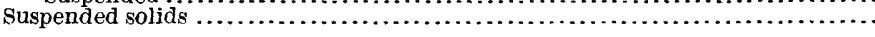 & 27,300 & (n......... \\
\hline Oxygen consumed: $\quad$ Seltled liquor. & & \\
\hline Total..................... & 6,000 & 33 \\
\hline Dissolved .. & 1,600 & 6 \\
\hline Suspended $\ldots \ldots \ldots \ldots \ldots \ldots$ & 4,400 & 40 \\
\hline Suspended solids .................. & 4,500 & 84 \\
\hline Oxygen consumed: & & \\
\hline 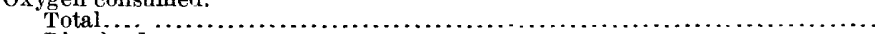 & 1,800 & 80 \\
\hline Dissolved & 1,600 & 0 \\
\hline 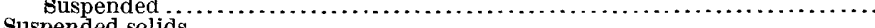 & 200 & 98 \\
\hline spended solids ........................... & 450 & 98 \\
\hline
\end{tabular}

The improvement of this effluent over that obtained without a coagulant is decided, but is hardly sufficient to warrant the extra cost of treatment. Previous studies had shown that it was necessary to add to the volume of waste on the surface of the filter at least 2 ounces of alum in order to bring about a satisfactory precipitation of the lime. Any less amount would not have produced a satisfactory precipitation in a short time. The total quantity filtered during the run was 370 gallons. This gives an amount of sulfate equal to a little over 2 grains per gallon for the entire run, or a consumption of 300 pounds of alum per million gallons. At a cost of 1 cent per pound (based on net weight of sulfate of aluminum in the crude compound) this would amount to $\$ 3$ per million gallons of waste, or 10 cents per ton of finished board. This additional cost for chemicals, together with the slightly additional expenditure for labor and water required by more frequent washing, would not seem to be justified in general by the slightly increased purity of the effluent. The results are given here 
and the cost estimated as a matter of record and in order to show what could be accomplished by the process if it were deemed desirable in any special case.

The second plan for preventing the small suspended particles in the liquor being drawn thru the surface was to use a surface layer of fine sand. A suitable grade of sand was obtained locally and screened thru a No. 20 screen. The sand thus prepared contained a considerable amount of rather fine materal. Mechanical analysis showed that it had an effective size of $0.26 \mathrm{~mm}$. and a uniformity coefficient of 2.0 .

A 6-inch layer of the sand was placed on the top of the filter and washt. After washing, the surface was examined and found to consist of a well-mixt layer of coarse and fine material. Two runs were made with the filter as thus prepared. The following are the average data obtained:

Data of test run of filler after addition of fine sand.

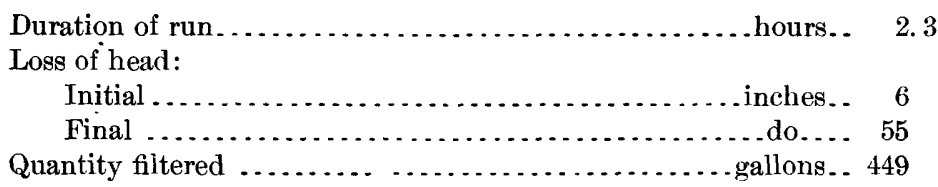

The appearance of these effluents was such that chemical analyses were not made. They were essentially like the others, and there was no advantage in the use of the layer of fine sand which could in any way offset the obvious disadvantage of the much shorter run.

THE SLIDGE.

Amount and composition.-Thruout the experiments, except for the first few runs, the dirty wash water from the filter was run back into the sedimentation tanks. Eventually, therefore, all the material removed from the waste liquor was accumulated in the bottom of these tanks. At the conclusion of the experiments, which consisted altogether of 12 runs, dealing with a total of 4,900 gallons of the waste, the liquor was drawn off from the tanks as far as possible and the depth of accumulated sludge and remaining liquor was measured. The average depth was found to be 6 inches. After thoro mixing a sample of the sludge was collected and allowed to stand in a glass cylinder for two hours. From a column of sludge 12 inches in depth a 2 -inch layer of clear liquid separated at the top, leaving the depth of sludge on the bottom 10 inches. Therefore the 6 inches of sludge and liquor left in the tank was conposed of 5 inches of sludge and 1 inch of water, so that 5 inches represents very closely the average depth of sludge in eaeh tank and will be used in the calculations which follow. 
Analysis of the sludge gave the following results:

Analysis of sludge resulting from filtration of strawboard waste.

Specific gravity .................................. 1.094

Total solids . . . . . . . . . . . . . . . . . 19.4

Volatile ................................do... 9.8

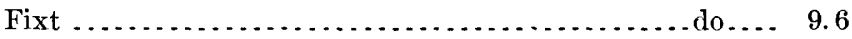

From these data the following results are obtained:

Sludge in tank....................................... 178

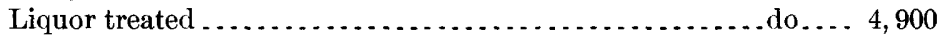

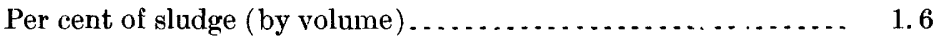

From 1,000,000 gallons of waste there will be obtained-

Sludge ....................................... $\quad 79$

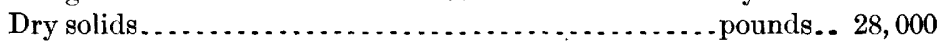

Organic solids ................................. 14, 100

Mineral solids ............................... do... 13,900

For each ton of strawboard there will be produced-

Sludge ...................................... 4.7

Dry solids.................................... pounds.. 1,680

A glance at Pl. I, $B$, will indicate what these figures mean. The piles of straw there shown represent three months' supply for a mill producing 30 tons of board per day. Over one-third of the total weight of this straw will appear in the waste liquor.

Properties and uses of the sludge.-As is indicated by the analysis, the sludge is a thick mud. It is dark muddy brown in color, and has the odor of straw. On exposure to the air it dries much more rapidly than would be expected, owing largely to the action of the air on the free lime. If allowed to dry in a mold, the resulting cast comes away clear and has taken a very clean impression of the mold. It is very brittle by itself. If, however, a little paper fiber be mixt with it before drying, the dry cast is fairly tough. Such a mixture could undoubtedly be used in many places as a cheap substitute for papiermaché.

The dry product had a specific gravity of 0.62 . It will readily absorb considerably more than its own weight of water. Its porous nature suggests its use as a heat insulator, particularly in refrigerators.

This material possesses a certain value as a fertilizer. It contains a considerable proportion of calcium carbonate, a substance heneficial to cultivated land. It also contains 0.34 per cent of phosphoric acid in an available form. Its loose, porous nature makes it particularly valuable for use on clay land, as such land is made much more porous by it and at the same time is sufficiently fine to retain the moisture well. This point was well brought out on examining one of the abandoned settling basins. This basin had originally been diked up about 6 feet 
above the surrounding fields, and had subsequently been completely filled with the sludge. On digging into this deposit, standing water was observed at a depth of less than 2 feet below the surface, altho the ground-water level in the adjacent fields was at least 6 feet lower and the field had not been flooded for over a year.

Some experiments have been made with this solid residue as a base for the production of a sulfur dye. Fusion of the substance with twice its weight of a mixture of one part of sulfur and two of sodium sulfide yields a mass containing a considerable proportion, perhaps 20 per cent, of a brown sulfur dye. Purification of the resulting dye from the mass of inert material was not attempted, and further study is required to determine the most satisfactory procedure for the preparation and purification of this dye, but enough has been done to indicate that a low-grade sulfur dye can be made from this waste material. It dyes unmordanted cotton a good warm shade of brown, is fast to hot soap and to sunlight, and compares favorably in color and fasitness with dyes on the market selling at 15 cents per pound.

Considerable attention has been given to the problem of finding profitable use for the residual organic matter which is the end product of the filtration processes here recommended. Altho the satisfactory solution of this problem would be highly desirable and would at once assure the treatment of all strawboard waste liquors, it must be remembered that this is merely a question incidental to the main problem. It is believed that the process of sedimentation, followed by mechanical filtration, essentially as described, furnishes by itself a solution of that problem which will prove of financial advantage to the manufacturers and of lasting benefit to all who have an interest in the purity of the streams below. It was therefore not deemed pertinent to the present investigation to pursue further the question of the utilization of the sludge. The suggestions here given, and particularly that in regard to the preparation of a dye, are merely intended to indicate the direction in which, according to the writer's views, future research would bring results of value.

RÉSUMÉ OF METHOD OF TREATMENT.

The following plan of treatment is recommended: The waste water from the beaters should be past thru a properly designed settling tank of such size that it will give a period of about one hour's storage. A tank built on the principle of the Dortmund tank would be preferable to any other, owing to its compactness and the possibility of continuous use. The tank should have a capacity of approximately 1,200 gallons for each ton of board produced per day by the mill.

The water should pass from the tank directly to the filters, which should be built in small units. The filters should have an available loss of head of at least 12 feet, and could be run at a rate of $100,000,000$ 
gallons per acre per day. This would necessitate a filter area of approximately 16 square feet per ton of board produced daily. This figure allows 10 per cent excess for repairs and washing.

The effluent should be pumped and used again for washing the filter and for beater wash water. It would at all times contain less impurity than does the very last water past from the beaters and its use during the early part of the washing process could do no possible harm. To insure a proper washing out of the last of the lime from the stock it would probably be found necessary to complete the washing with fresh water. In any case a saving of one-half to two-thirds of the amount of wash water now used could be realized, the amount of waste liquor being correspondingly reduced. The water used in washing the filter should be returned to the sedimentation tank and would require no further treatment.

The sludge from the sedimentation tank could be most expeditiously dealt with by filter pressing. There remain a fairly dry and hard press cake, which would require disposal unless some profitable use for it be found. Under the influence of the air and sun this material is speedily resolved into mineral matter, forming a sort of soil. It could be spread upon low land in thin layers and would then take care of itself.

Instead of being filter prest, the sludge might be discharged upon snaall areas of sandy soil where such are available or even upon some. what larger areas of less porous soil, and allowed to dry out by draining and evaporation. The dry layer of sludge could then be removed and disposed of. No accumulation of the wet material should be allowed. When once dried out and subjected to the action of the sunlight and air it soon becomes harmless, but in deep beds and constantly covered with water it is subject to all the offensive putrefaction described in the ease of the sedimentation fields. This process of spontaneous draining and drying out would probably be found the cheaper, but would require a considerable area of suitable land and would also involve more careful supervision. The amount of land required would depend wholly on the quality of the drainage. For average conditions it may be roughly estimated at 1,000 square feet per ton of board produced by the mill daily. The dried sludge would require removal before the application of more sludge.

CHARACTER OF WASTE WATER AFTER TREATMENT.

The quality of the effluent from the proposed process is not all that could be desired. In spite of the fact that it is possible to remove over 90 per cent of the suspended organic matter present in the liquor the resulting effluent is still putrescible. That is, a bottle of the liquor shut up air-tight and kept at a warm temperature will in the course of a few days undergo putrefactive fermentation. The putrefaction is 
rather slow, however, and not offensive. In admixture with an equal volume of tap water the effluent does not putrefy even when inoculated with a small amount of sewage.

The fact that the effluent is practically free from gross suspended solids-that is, solids which will settle ont on the bed of the stream-is of greater significance than the analytical data. As was pointed out in the earlier discussion of the problem (p. 8), by far the greater part of the damage done to the polluted streams is brought about by the deposit of naterial in the stream beds. The effluent which has past the treatment here outlined will contain no material capable of settling out even in slack water.

The conclusion is therefore justified that the discharge of this effluent into a stream whose minimum flow equals in volume the flow from the mill would not produce a nuisance. With no allowance for a possible diminution of the amount of wash water, if used as suggested above, this means that the minimum stream flow must be at least 0.05 cubic foot per second per ton of board produced daily at the mill. A minimum flow of 0.1 cubic foot per second per daily ton would therefore provide for a generous factor of safety if the stream is reasonably unpolluted at the point of discharge.

The discharge of such an effluent into a stream highly polluted with sewage would probably be accompanied by an aggravation of the conditions already existing. There would, as usual, be a precipitation of the sewage material by the lime of the effluent. In all fairness it could be maintained that the organic matter of the effluent was not contributing to the nuisance. If, therefore, it should be decided that the addition of lime to a sewage-polluted stream constitutes a nuisance, further treatment of the effluent would be required to remove this caustic lime. If, on the other hand, as would seem to be reasonable, it should appear that the real pollution of the stream lay in the sewage and the lime was incidental and was there by right, there would be no reason for such further treatment.

COST OF THE PROCESS.

The cost of the process recommended can not be discust in detail at this time. It would be largely the cost of installation. The design and construction of a suitable plant require expert attention and the cost of the plant would depend somewhat on local conditions. The cost of maintenance would be slight. The cost of additional pumping to supply wash water-say 5 per cent more than the present amount pumped-can be determined readily. The services of one man, who could also assist in the mill part of the time, would be a sufficient addition for running the plant. The power necessary to pump the sludge thru the filter presses, if that plan were adopted, would not be noticeable in comparison with the total power used in the mill. If the sludge 
were disposed of by the other plan, evaporation and drying in the field, the services of another man would be required.

Ir conclusion, the following summary of the chief points of the present paper may be made:

\section{SUMMARY.}

The present method employed for the treatment of strawboard waste liquor, that of sedimentation in large fields, is unsatisfactory and expensive and proceeds on a wrong principle.

The filtration of the liquor thru sand, so-called mechanical filtration, but without coagulants, after a short period of sedimentation will remove 93 per cent of the suspended organic solids and 98 per cent of the total suspended matter determined as turbidity.

Actual experiments have shown that the resulting effluent can be discharged into an equal volume of reasonably pure water without cresting a nuisance. In particular, there will be no sedimentation of organic matter. If its discharge into a seriously polluted stream should bring about precipitation of sewage matter and consequent nuisance, the blame should in all equity be fixt on those contributing the sewage.

The sludge resulting from the sedimentation tanks, after pressing or spontaneous drying, is innocuous and makes good soil. It has some value as a fertilizer and is particularly valuable to mix with the clay soils of the Middle West to render them more porous. Other uses for this material are suggested, but they require further study.

The cost of the entire process is sufficiently low to admit of its adoption wherever stream pollution is serious. 



\section{CLASSIFICATION OF THE PUBLICATIONS OF THE UNITED STATES GEOLOGICAL SURVEY.}

[Water-Supply Paper No. 189.]

The serial publications of the United States Geological Survey consist of (1) Annual Reports, (2) Monographs, (3) Professional Papers, (4) Bulletins, (5) Mineral Resources, (6) Water-Supply and Irrigation Papers, (7) Topographic Atlas of United States-folios and separate sheets thereof, (8) Geologic Atlas of United Statesfolios thereof. The classes numbered 2, 7, and 8 are sold at cost of publication; the others are distributed free. A circular giving complete lists can be had on application.

Most of the above publications can be obtained or consulted in the following ways:

1. A limited number are delivered to the Director of the Survey, from whom they can be obtained, free of charge (except classes 2,7 , and 8), on application.

2. A certain number are delivered to Senators and Representat for distribution.

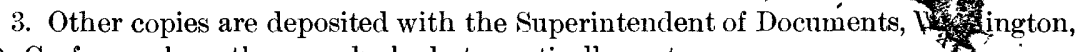
D. C., from whom they can be had at.practically cost.

4. Copies of all Government publications are furnished to the principal pablic libraries in the large cities thruout the United States, where they can be consuliad by those interested.

The Professional Papers, Bulletins, and Water-Supply Papers treat of a variety of subjects, and the total number issued is large. They have therefore been classified into the following series: A, Economic geology; B, Descriptive geology; C, Systematic geology and paleontology; D, Petrography and mineralogy; E, Chemistry and physics; F, Geography; G, Miscellaneous; H, Forestry; I, Irrigation; J, Water storage; K, Pumping water; L, Quality of water; M, General hydrographic investigations; N, Water power; O, Underground waters; P, Hydrographic progress reports. This paper is the seventeenth in Series $\mathrm{L}$, the complete list of which follows (WS= Water-Supply Paper):

SERIES L, QUality of WATER.

WS 3. Sewage irrigation, by (r. W. Rafter. 1897.100 pp., 4 pls. (Out of stock.)

WS 22. Sewage irrigation, Pt. II, by G. W. Rafter. 1899.100 pp., 7 pls. (Out of stock.)

WS 72. Sewage pollution near New York City, by M. O. Leighton. 1902.75 pp., 8 pls.

WS 76. Flow of rivers near New York City, by H. A. Pressey. 1903.108 pp., 13 pls.

WS 79. Normal and polluted waters in northeastern United States, by M. O. Leighton. 1903. 192 pp., $15 \mathrm{pls}$.

WS 103. Review of the laws forbidding pollution of inland waters in the United States, by E. B. Goodell. 1904. $120 \mathrm{pp}$.

WS 108. Quality of water in the Susquehanna River drainage basin, by M. O. Leighton, with an introductory chapter on physiographic features, by G. B. Hollister. 1904.76 pp., 4 pls.

WS 113. Strawboard and oil wastes, by R. L. Sackett and Isaiah Bowman. 1905. 52 pp., 4 pls.

WS 121. Preliminary report on the pollution of Lake Champlain, by M. O. Leighton. 1905.119 pp., $13 \mathrm{pls}$.

WS 144. The normal distribution of chlorine in the natural waters of New York and New England, by D. D. Jackson. 1905. $31 \mathrm{pp} ., 5 \mathrm{pls}$

WS 151. Field assay of water, by M. O. Leighton. 1905. 77 pp., 4 pls.

WS 152. A review of the laws forbidding pollution of inland waters in the United States, second edition, by E. B. Goodell. 1905. $149 \mathrm{pp}$. 
WS 161. Quality of water in upper Ohio River basin and at Erie, Pa., by S. J. Lewis. 1906.114 pp., 6 pls.

WS 179. Prevention of stream pollution by distillery refuse, based on investigations at Lynchburg, Ohio, by Herman Stabler. 1906. 34 pp., 1 pl.

WS 185. Investigations on the purification of Boston sewage, by C. E. A. Winslow and Earle B. Phelps. 1906. - pp.

WS. 186. Stream pollution by acid-iron wastes, a report based on investigations made at Shelby, Ohio, by Herman Stabler. $1906.36 \mathrm{pp} ., 1 \mathrm{pl}$.

WS. 189. The prevention of stream pollution by strawbourd waste, by Earle Bernard Phelps. 1906. 29 pp., 2 pls.

Correspondence should be addrest to

The Director,

United States Geological Survey,

DeCember, 1906.

$\mathrm{O}$

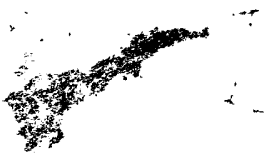

